\title{
Myelin Plasticity and Repair: Neuro-Glial Choir Sets the Tuning
}

\author{
Remi Ronzano ${ }^{1}$, Melina Thetiot ${ }^{1,2}$, Catherine Lubetzki ${ }^{1,3}$ and Anne Desmazieres ${ }^{1 *}$ \\ 'Institut du Cerveau et de la Moelle épinière, Sorbonne Universités UPMC Université Paris 06, CNRS UMR7225-Inserm \\ U1127, Paris, France, ${ }^{2}$ Unit Zebrafish Neurogenetics, Department of Developmental \& Stem Cell Biology, Institut Pasteur, \\ CNRS, Paris, France, ${ }^{3}$ Assistance Publique-Hôpitaux de Paris, Hôpital Pitié-Salpêtrière, Paris, France
}

The plasticity of the central nervous system (CNS) in response to neuronal activity has been suggested as early as 1894 by Cajal (1894). CNS plasticity has first been studied with a focus on neuronal structures. However, in the last decade, myelin plasticity has been unraveled as an adaptive mechanism of importance, in addition to the previously described processes of myelin repair. Indeed, it is now clear that myelin remodeling occurs along with life and adapts to the activity of neuronal networks. Until now, it has been considered as a two-part dialog between the neuron and the oligodendroglial lineage. However, other glial cell types might be at play in myelin plasticity. In the present review, we first summarize the key structural parameters for myelination, we then describe how neuronal activity modulates myelination and finally discuss how other glial cells could participate in myelinic adaptivity.

Keywords: myelin, oligodendrocytes, glia, microglia, astrocyte, myelination, plasticity, remyelination

\section{OPEN ACCESS}

Edited by:

Domna Karagogeos, University of Crete, Greece

Reviewed by: Wiebke Möbius, Max Planck Institute for Experimental Medicine, Germany Enrica Boda,

University of Turin, Italy

*Correspondence: Anne Desmazieres anne.desmazieres@icm-institute.org

Received: 26 December 2019 Accepted: 12 February 2020 Published: 28 February 2020

Citation: Ronzano R, Thetiot M, Lubetzki C and Desmazieres A (2020) Myelin Plasticity and Repair: Neuro-Glial Choir Sets the Tuning. Front. Cell. Neurosci. 14:42. doi: 10.3389/fncel.2020.00042

\section{INTRODUCTION}

Myelin is a feature of jawed vertebrates (Zalc et al., 2008), though it has also been acquired independently along with evolution by few invertebrate taxa (Hartline and Colman, 2007). Myelin is formed by lipid-rich membrane layers wrapped around axons, providing electrical insulation and metabolic support. This process ensures fast saltatory conduction (Waxman and Foster, 1980), reaching velocities that would otherwise require giant axons (Hartline and Colman, 2007). Despite its energy cost (Harris and Attwell, 2012), myelin correlates with increased population fitness, more efficient behaviors and increased body size.

In vitro and in vivo models showed that the axonal diameter is a key determinant for myelination (Lee S. et al., 2012; Goebbels et al., 2017; Mayoral et al., 2018). The usual threshold for myelinated axon in the peripheral nervous system (PNS) is 1 micron (Matthews, 1968). However, theoretical predictions suggest that myelination can increase axonal conduction with a diameter as low as $0.2 \mu \mathrm{m}$ (Waxman and Bennett, 1972), which fits with central nervous system (CNS) myelination, where axons with diameters from $0.4 \mu \mathrm{m}$ can be myelinated (Hildebrand et al., 1993). At a given axonal diameter, the conduction velocity of an action potential depends on the structural characteristics of myelin. The major parameters are the g-ratio (the axonal diameter divided by the total outer diameter of the fiber; Smith and Koles, 1970), and the internodal length (Huxley and Stampfli, 1948). Mean measured value and predicted optimum for the g-ratio are between 0.6 and 0.7 in the PNS and slightly above in the CNS white matter (Rushton, 1951; Smith and Koles, 1970; Waxman and Swadlow, 1976; Michailov et al., 2004; Chomiak and Hu, 2009). The conduction velocity also increases with the internodal length until it reaches a plateau at 1,000 $\mu \mathrm{m}$ (Brill et al., 1977; Moore et al., 1978). In the PNS, the majority of internodes exceed $500 \mu \mathrm{m}$ 
(Hildebrand et al., 1994), and variations in internodal length have little effect on conduction velocity ( $\mathrm{Wu}$ et al., 2012; Simpson et al., 2013). In the CNS, internodes are much shorter, on average $50 \mu \mathrm{m}$ in gray matter and $150 \mu \mathrm{m}$ in white matter (Tomassy et al., 2014; Arancibia-Cárcamo et al., 2017; Stedehouder et al., 2017, 2019), and changes in their length have a higher impact on conduction velocity (Etxeberria et al., 2016). Thus, in the CNS, structural characteristics allow for modulation of conduction velocity.

In the CNS, in vitro (Watkins et al., 2008) as well as in vivo experiments (Czopka et al., 2013) have demonstrated that myelinating oligodendrocytes (OLs) establish myelin sheaths in only a few hours. Following this step, between 20 and 60 myelin sheaths per OL are stabilized in rodents (Matthews and Duncan, 1971; Chong et al., 2012), and about 15 per OL in zebrafish. The deposition of the successive myelin layers is led by the inner tongue which wraps around the axon and extends laterally (Snaidero et al., 2014). The dynamics of the actin cytoskeleton appears finely regulated to trigger myelin wrapping, with an actin polymerization at the leading edge of the inner tongue and subsequent depolymerization (Nawaz et al., 2015; Zuchero et al., 2015). Moreover, defects in adhesion molecules expressed at myelin membranes and axolemma affect the number, the length and the folding of myelin sheaths, disrupting target recognition and myelin extension around and along axons (Djannatian et al., 2019; Hughes and Appel, 2019; Klingseisen et al., 2019).

Myelination has long been viewed as a process ending in young adults. However, in the CNS, though some structures like the optic nerve are fully myelinated (Honjin et al., 1977; Bartsch et al., 1997; Dangata and Kaufman, 1997), most of the areas exhibit partial myelination. The corpus callosum contains $20-40 \%$ of unmyelinated fibers in adult rodents (Seggie and Berry, 1972; Gravel et al., 1990; Olivares et al., 2001), and the myelination profile of excitatory as well as inhibitory neurons show discontinuous patterns in the cortical and hippocampal areas (Tomassy et al., 2014; Micheva et al., 2016; Stedehouder et al., 2017, 2019). These myelination patterns have been suggested to regulate action potentials (APs) arrival at the presynaptic compartment (Salami et al., 2003) and provide metabolic support to fast-spiking neurons that have a high energy demand (Micheva et al., 2016). Incomplete myelination should allow for myelin plasticity, which could potentiate specific connections or provide additional metabolic support in the CNS by the addition of myelin on specifically activated networks.

\section{NEURONAL ACTIVITY SHAPES MYELINATION PROFILE ALONG WITH LIFE}

The role of neuronal activity in modulating myelination was first suggested more than 50 years ago by the effect of light deprivation on mouse optic nerves (Gyllensten and Malmfors, 1963). Later on, modulation of the oligodendroglial lineage through neuronal activity was shown in vitro using neurotoxins and electrical stimulations (Barres and Raff, 1993; Demerens et al., 1996; Fields and Stevens, 2000; Stevens et al., 2002). More recently, the relationship between these processes has been extensively studied with growing evidence that neuronal activity plays a key role in the modulation of every step of myelination both during development and in adulthood.

\section{The Oligodendroglial Lineage Can Perceive the Neuronal Activity}

Neuronal activity can modulate oligodendrocyte progenitor cells (OPCs) proliferation, maintenance and differentiation in zebrafish and mammals (Hill et al., 2014; Zonouzi et al., 2015; Hamilton et al., 2017; Hoche et al., 2019). Glutamatergic and GABAergic neurons have been shown to form bona fide synapses on OPCs in rodents (Bergles et al., 2000; Lin and Bergles, 2004) and humans (Gallo et al., 2008), with neuronal inputs on OPCs being consistent between brain regions (Mount et al., 2019). The activity of afferent neurons through the activation of either AMPA or GABA receptors is widely involved in the control of OPCs fate and self-maintenance along CNS development (Mangin et al., 2012; Zonouzi et al., 2015; Balia et al., 2017; Kougioumtzidou et al., 2017; Chen et al., 2018; Figure 1). Furthermore, OPCs are not only sensitive to the presence of neuronal activity, but also to the pattern of activity, which modulates differently their proliferation and differentiation (Nagy et al., 2017). Although the involvement of neuron-OPCs synapses has been largely documented, non-synaptic junctions between neurons and OPCs have also been involved in the facilitation of OPCs differentiation in vitro (Wake et al., 2015; Figure 1). The control of OPCs proliferation and differentiation has been showed to depend on $\mathrm{Ca}^{2+}$ signals triggered by neuronal activity in vitro in rodents (Wake et al., 2011) and in vivo in zebrafish (Hoche et al., 2019). However, depending on the developmental stage and the anatomical area studied, OPCs respond differently to neuronal activity, possibly related to their heterogeneous expression of voltage-gated channels and receptors to neurotransmitters (Káradóttir et al., 2008; Hoche et al., 2019; Spitzer et al., 2019).

\section{Neuronal Activity Modulates Axon Selection as Well as Myelination Pattern}

Highly specific selection of the axonal segments to be myelinated is necessary to lead to adequate myelination patterns. It has been shown in vitro and in vivo in mice and zebrafish that the choice of the target axons is promoted by neuronal activity (Hines et al., 2015; Wake et al., 2015; Mitew et al., 2018; Figure 1). In zebrafish, the maintenance of nascent myelin sheaths is increased on electrically active axons (Hines et al., 2015). Neuronal activity can also regulate the number of myelin sheaths per OL in zebrafish (Mensch et al., 2015) and their length in mouse optic nerves (Etxeberria et al., 2016). Activitydependent myelination acts through the release of axonal vesicles (Hines et al., 2015; Mensch et al., 2015; Wake et al., 2015; Etxeberria et al., 2016) triggering $\mathrm{Ca}^{2+}$ signals in OLs. In zebrafish, $\mathrm{Ca}^{2+}$ signals along myelin sheaths regulate their stabilization and growth in an axonal activity-dependent manner 


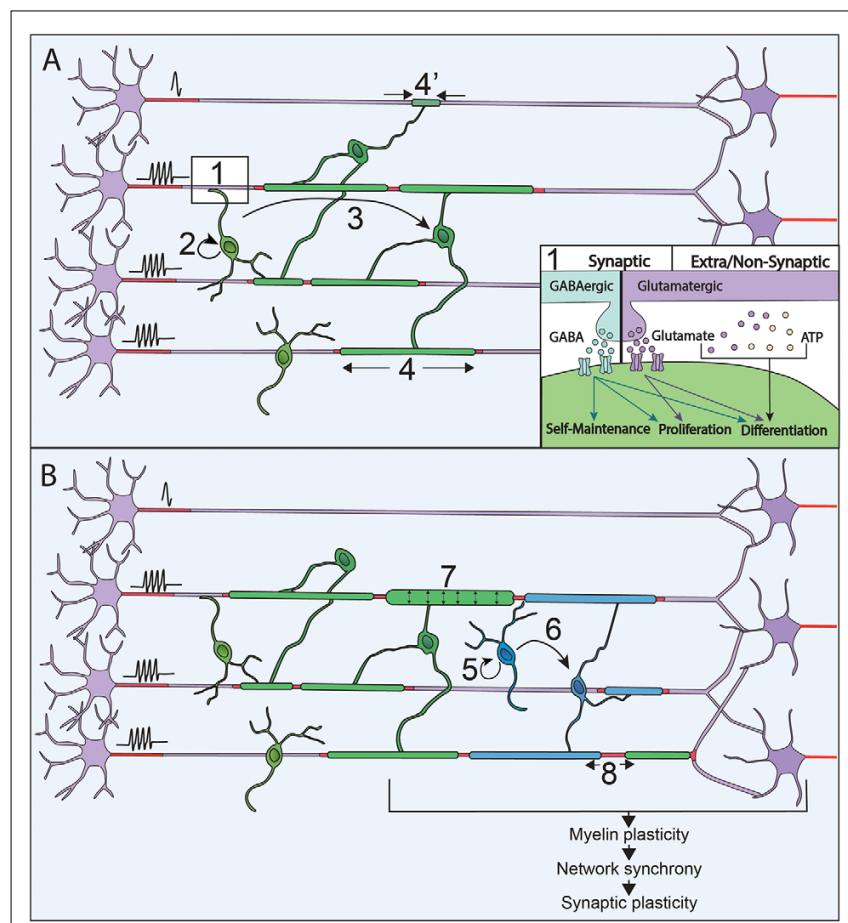

FIGURE 1 | Neuronal activity modulates myelination processes along with life. (A) Neuronal activity is sensed through synapses and extra/ non-synaptic junctions between neurons and oligodendrocyte progenitor cells (OPCs; 1). Neurons release GABA (blue) or Glutamate (purple) that activate respectively $\mathrm{GABA}_{A}$ and $\mathrm{AMPA}$ receptors at neuron-OPC synapses. Vesicles of ATP (orange) can also be released by neurons and modulate OPCs physiology at extra-synaptic and non-synaptic junction together with glutamate. Neuronal activity modulates every step of myelination during development: OPCs maintenance and proliferation (2), OPCs differentiation in OLs (3) and myelin sheaths stabilization and extension (4 and 4'). (B) In the adult, OPCs are maintained and their proliferation (5), as well as differentiation (6), can be promoted by an increase of neural activity when performing a new task. This increase in neuronal activity can also modulate the characteristics of myelin sheaths that are already formed by increasing their thickness (7) and modifying the nodal gaps (8).

(Baraban et al., 2018; Krasnow et al., 2018). The frequency, the duration and the amplitude of $\mathrm{Ca}^{2+}$ signals appears to be crucial for myelination and correlates with axonal activity (Krasnow et al., 2018). Based on what has been done on NG2 cells (Nagy et al., 2017), deciphering the effects of various neuronal firing patterns on OLs myelination may result in a better understanding of these complex modulations. However, the prominence of neuronal activity in the control of myelination needs to be weighted, as myelin increase could also reflect concurrent growth of axonal arborization (Stedehouder et al., 2018). Moreover, non-neuronal activity related mechanisms concomitantly participate to axon selection during myelination (Rosenberg et al., 2008; Bechler et al., 2018; Mayoral et al., 2018) and, for some neuronal populations, myelination occurs independently of neuronal activity (Koudelka et al., 2016). It can, therefore, be considered that neuronal activity is rather acting as a modulator allowing to adapt myelination pattern to the activity of the neuronal networks.

\section{Myelination in Adulthood as an Adaptive Mechanism}

In mice, OPCs keep proliferating and differentiating in adult CNS, with $5-20 \%$ of OLs generated during adulthood (Rivers et al., 2008; Kang et al., 2010; Simon et al., 2011; Young et al., 2013). The OLs generated in adulthood could contribute to cellular turnover or adaptive myelination. However, in mice, except in the optic nerves, OLs survival rate is over $90 \%$ at 8 months suggesting that the new OLs generated may rather participate in adaptive processes (Tripathi et al., 2017). Remodeling of existing myelin has first been observed, in social isolation of adult mice, where induction of behavioral changes correlate with myelin sheath thinning and transcriptional changes in OLs in the medial prefrontal cortex (Liu et al., 2012). Myelin plasticity could further be associated with changes in internodal or nodal gap length, both of which have been described to tune conduction velocity (Ford et al., 2015; Arancibia-Cárcamo et al., 2017; Figure 1). Indeed, myelin sheath length can be remodeled once it is established; however, these changes are relatively rare in adulthood and sensory enrichment failed to induce any measurable changes in sheath length in rodents (Hill et al., 2018; Hughes et al., 2018). Alternatively, conduction velocity could be tuned by changes in nodal gap length, which can be modulated in adult mice (Dutta et al., 2018), upon neuronal activity changes (Cullen et al., 2019; Korrell et al., 2019).

So far, adaptive myelination has mainly been associated with the generation of new OLs and the addition of new myelin sheaths (Figure 1). First, the learning of complex motor tasks has been shown to trigger OPCs proliferation, OLs maturation and myelin deposition (Sampaio-Baptista et al., 2013; McKenzie et al., 2014). Furthermore, in the same paradigm of complex wheel running, OPCs differentiation occurred within the range of a few hours (Xiao et al., 2016). Relatively short optogenetic stimulations of the premotor areas at a physio mimetic frequency triggered OPCs proliferation, oligodendrogenesis and myelin thickening, coupled to behavioral improvement (Gibson et al., 2014), corroborating the involvement of adaptive myelination in motor learning. Lastly, spatial learning was shown to trigger adaptive myelination, and impairment in adaptive myelination leads to defect in memory consolidation (Steadman et al., 2020) and short term memory (Geraghty et al., 2019). In humans, a link between neuronal activity and the addition of new myelin sheaths in adult CNS has been shown by studies on healthy subjects achieving motor and memorization tasks. White matter microstructural changes were demonstrated (Scholz et al., 2009; Takeuchi et al., 2010), and the amplitude of the effect correlated with the training duration (Taubert et al., 2010). These changes could be due to myelin deposition per se or reflect axonal remodeling (Zatorre et al., 2012). The origin of the newly added myelin has been investigated by immunohistochemical studies, which provided evidence of proliferating OPCs in the adult brain (Geha et al., 2010). This was further supported by studies on non-human primates showing an increase in the number of OLs during adulthood (Peters and Sethares, 2004; Peters et al., 2008). Alternatively, myelin could also arise from pre-existing 
OLs persisting into adulthood, as identified in humans (Yeung et al., 2014; Fard et al., 2017; Jäkel et al., 2019). Thus, although adaptive myelination also occurs in the human brain, to which extent mechanisms are shared between rodents and humans is still under debate.

Myelin adaptation could be involved in the fine-tuning of neural network synchrony, and action potential arrival at the presynaptic compartment (Pajevic et al., 2014; Ford et al., 2015), that are thought to govern learning and memory (Feldman, 2012; Kandel et al., 2014; Korte and Schmitz, 2016). The effect of adaptive myelination on short term memory and memory consolidation supports this hypothesis (Geraghty et al., 2019; Steadman et al., 2020), but future studies will be needed to determine how adaptive myelination modulates the electrophysiological parameters of specific parts of neuronal circuits, and further creates a synchronization at specific connections. Moreover, feedback signals from the myelinated axon/neuron allowing for the fine control of myelin addition and removal should be required to tune finely AP arrival at the synapses and further synchronize the circuits. Until now, they remain unknown, with previous works on synaptic plasticity being a potential source of inspiration to investigate them (Fields et al., 2014).

Newly added myelin sheaths could further provide metabolic support to axons (Fünfschilling et al., 2012; Lee Y. et al., 2012; Meyer et al., 2018), the metabolic supply being regulated by neuronal activity (Saab et al., 2016). This myelin addition probably would not result in a global energetic advantage (Harris and Attwell, 2012), but might be needed to generate fast-spiking firing discharges and thus allow for precise axonal firing (Micheva et al., 2016; Moore et al., 2019).

Although the molecular mechanisms inducing adaptive myelination in the adult are still unclear, recent studies showed the involvement of two factors, endothelin (Swire et al., 2019) and BDNF (Geraghty et al., 2019). Neuronal activity triggers an increase in blood flow that in turn increases endothelin expression by endothelial cells (Walshe et al., 2005; Pandit et al., 2015). This has been shown to increase myelination ex vivo (Yuen et al., 2013). In adult mice, endothelin rescues myelination defects triggered by social isolation, thus confirming its involvement in adaptive myelination (Swire et al., 2019). BDNF had first been suggested to modulate activity-dependent myelination (Lundgaard et al., 2013) and later showed to be a regulator of adaptive myelination (Geraghty et al., 2019). It is produced by neurons in an activity-dependent manner (Balkowiec and Katz, 2000; Hartmann et al., 2001; Dieni et al., 2012) and can be released by synaptic vesicles (Park et al., 2014). Thus, BDNF secretion could specifically trigger adaptive myelination along activated axons. However, BDNF is not only released by neurons, but also by astrocytes (Fulmer et al., 2014; Zhang et al., 2014) and microglial cells (Parkhurst et al., 2013). These complex BDNF signals might have to be integrated by the oligodendroglial lineage when it comes to adaptive myelination, as well as in injury (McTigue et al., 1998; Ikeda et al., 2002; Ramos-Cejudo et al., 2015). Lastly, OPCs themselves could modulate myelination and myelin plasticity directly or indirectly, in particular through the secretion of BDNF or retinoic acid (Tanaka et al., 2009; Parolisi and Boda, 2018; Goncalves et al., 2019). Adaptive myelination and repair should thus not be considered only as direct neuronal crosstalk with the oligodendroglial lineage, but also in regard to their direct cellular environment.

\section{MYELINATION AND REPAIR ARE ALSO MODULATED BY OTHER NEURO-GLIAL INTERACTIONS}

The crosstalk between neuron and glia is complex and probably critical when it comes to myelination regulation, in adaptive processes and repair. Astrocytes and microglial cells are known to participate in (re)myelination modulation and have been described to detect neuronal activity (for review, Domingues et al., 2016; Adaikkan and Tsai, 2019; Bar and Barak, 2019; Molina-Gonzalez and Miron, 2019). Although astrocytes and microglia may be involved in molecular mechanisms modulating adaptive myelination, the understanding of their impact on adult myelination processes is still limited.

\section{Control of Myelination and Myelin Plasticity by Astrocytes}

Astrocytes are the most abundant CNS glial cell type, with a major role in metabolic support, homeostatic functions, assembly and modulation of synapses, Blood-Brain Barrier (BBB) integrity and nervous tissue scaring. They further participate in neuronal activity and myelination regulation, in plasticity and learning (for review, Barres, 2008; Fields et al., 2014). Astrocytes are heterogeneous, with protoplasmic astrocytes, in the gray matter, interacting with synapses and $\mathrm{BBB}$, and fibrous astrocytes, in the white matter, contacting nodes of Ranvier and blood vessels (for review, Sofroniew and Vinters, 2010).

Astrocytes have been described to regulate all oligodendroglial lineage steps, from OPCs proliferation to differentiation and myelination (for review, Domingues et al., 2016; Figure 2), in particular by secretion of various factors such as IGF1, CNTF, CXCL1, TIMP-1 and LIF (Gard et al., 1995; Stankoff et al., 2002; Ye et al., 2004; Padovani-Claudio et al., 2006; Modi et al., 2013; Jiang et al., 2016). Astrocytic role in myelination is partly dependent on neuronal activity, with the activity-dependent neuronal release of ATP triggering the secretion of astrocytic LIF factor, which further promotes OL survival and myelination (Ishibashi et al., 2006). Astrocytes also provide some lipids necessary to support the metabolic costs of myelination (Camargo et al., 2017) and promote OLs survival and maturation through direct physical contacts (Sakurai et al., 1998; Corley et al., 2001). They further connect with oligodendrocytes through connexins necessary for myelin maintenance and support of OLs $\mathrm{K}^{+}$buffering during neuronal activity (Menichella et al., 2006; Orthmann-Murphy et al., 2008; Tress et al., 2012). Once myelin is formed, astrocytes further play a role in myelin plasticity by regulating myelin thickness and nodal gap length (Dutta et al., 2018). Lastly, astrocytes control local blood flow depending on neuronal activity (for review, Nortley and Attwell, 2017) and could thus further be involved 


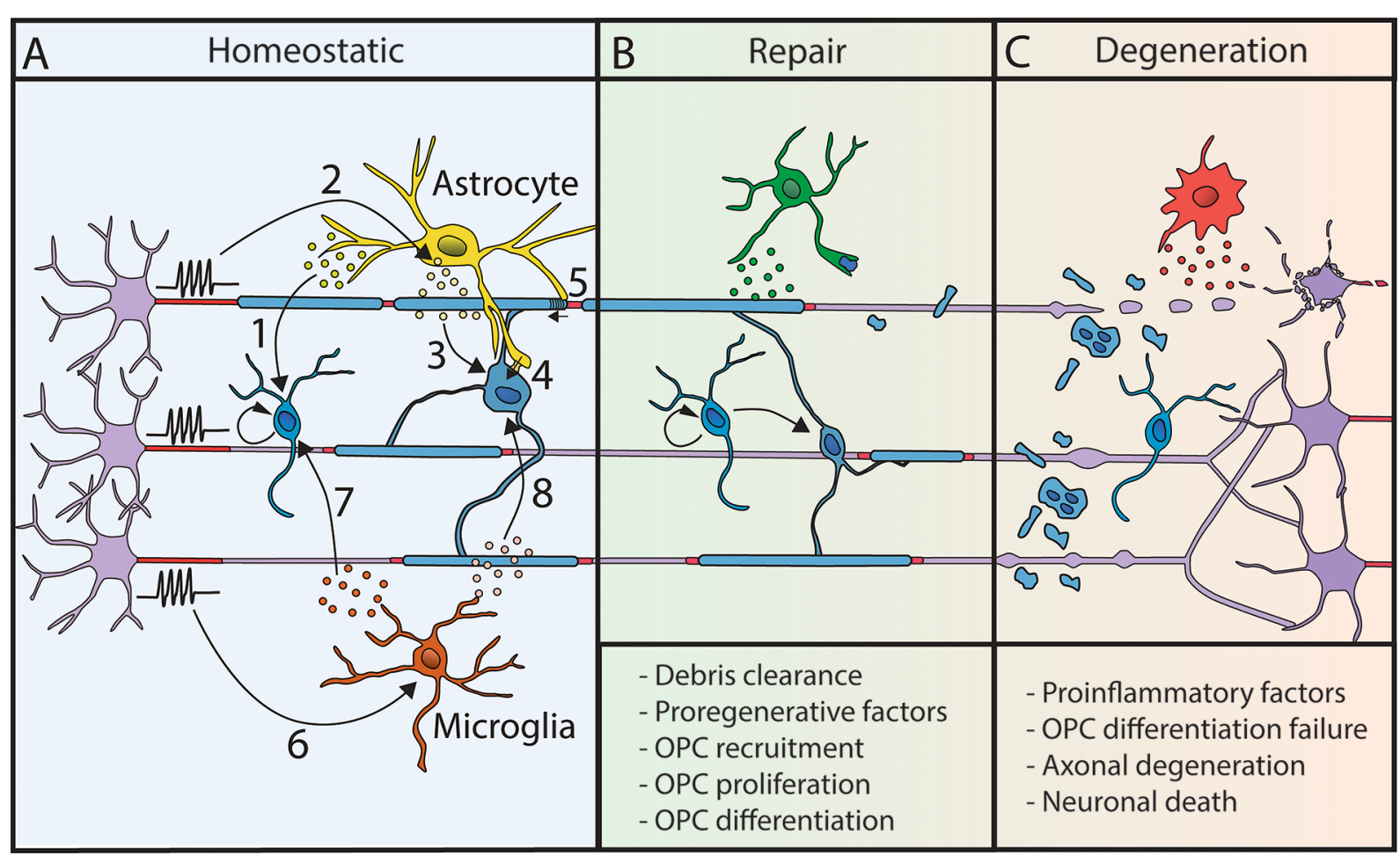

FIGURE 2 | Myelination processes are modulated by other glial cells. (A) In homeostatic conditions, astrocytes and microglial cells modulate myelin deposition. Astrocytes release factors regulating OPC proliferation (1). Neuronal activity triggers LIF release by astrocytes (2), which promotes myelination (3). Moreover, astrocytes are metabolically coupled to OLs (4) and modulate conduction velocity by acting on myelin thickness and nodal length (5). Microglial cell behavior is modulated by neuronal activity (6). They release factors that promote OPC proliferation and differentiation (7) and activate myelination (8). (B) Following demyelination, glial cells can promote repair by the clearance of myelin debris and the release of pro-regenerative factors. (C) However, their sustained proinflammatory activity can lead to repair failure and neurodegeneration.

in the indirect control of adaptive myelination by vasculature (Swire et al., 2019).

Astrocytes also play a complex role in demyelination and repair (Figure 2). They have been described to be rather beneficial in vitro, as well as in vivo, in chemically-induced demyelinating mouse models (Franklin et al., 1991; Selvaraju et al., 2004; Kramann et al., 2019). Following demyelination, they attract OPCs, promote their proliferation and differentiation (Omari et al., 2005; Patel et al., 2012). In contrast, astrocytes might play an inhibitory role in remyelination, in particular by inhibiting OLs maturation (Blakemore et al., 2003; Back et al., 2005; Sloane et al., 2010). They can further promote proinflammatory responses, circulating immune cell recruitment through $\mathrm{BBB}$ and modulate the number of activated microglial cells (Brambilla et al., 2014; Kim et al., 2014; Eilam et al., 2018). The complex role played by astrocytes, related to their phenotype, further depends on environmental cues and interaction with surrounding cells (Liddelow et al., 2017).

\section{Control of Myelination and Myelin Plasticity by Microglia}

Microglial cells are the resident immune cells of the CNS, where they represent $5-10 \%$ of the cells (Lawson et al., 1990). They continually monitor their environment (Nimmerjahn et al.,
2005), and play complex roles in neuroplasticity, homeostasis, host defense, healing, debris clearance and peripheral cell recruitment (for review, Colonna and Butovsky, 2017; Prinz et al., 2019). They can adopt different phenotypes, with environmentdependent transcriptional profiles (Gosselin et al., 2014, 2017), and proinflammatory to pro-regenerative polarization (Miron and Franklin, 2014), though a strict dichotomy is an inadequate vision (Ransohoff, 2016). Microglial cells are further sensitive to neuronal activity (Li et al., 2012; Liu et al., 2019; Stowell et al., 2019; Cserép et al., 2020). Altered microglia activity at different stages of life is associated with developmental and acquired neurological pathologies and can impair the plasticity-related process and cognitive function (Morris et al., 2013).

In homeostatic condition, microglia can support survival, differentiation, myelinogenesis, and homeostasis of the oligodendroglial lineage (Hamilton and Rome, 1994; Butovsky et al., 2006; Pasquini et al., 2011; Shigemoto-Mogami et al., 2014; Hagemeyer et al., 2017; Wlodarczyk et al., 2017; Figure 2). Activated microglia associated with myelin deficits has further been described in neurodevelopmental disorders and mental conditions (Garey, 2010; Morgan et al., 2010; Janova et al., 2018; Bar and Barak, 2019; Barak et al., 2019). These defects might be partly related to a lack of adaptive myelination. Indeed, microglia activation state is modulated by neuronal activity 
(Iaccarino et al., 2016; Adaikkan et al., 2019; Giorgetti et al., 2019; Martorell et al., 2019; Garza et al., 2020), and has been shown to modulate adaptive myelination in adult (Geraghty et al., 2019).

In demyelinating diseases, microglial activation is an early hallmark in multiple sclerosis (MS) together with axonal damage even prior to demyelination (Howell et al., 2010; Nikić et al., 2011). Microglia can have a dual role in repair, either impairing or promoting myelination in MS and its models in rodents (for review, Miron, 2017) depending on its phenotype (proinflammatory or pro-regenerative; Miron et al., 2013; Locatelli et al., 2018). It is considered that the pro-regenerative/pro-remyelinating effect of microglia might be related both to the secretion of pro-myelinating factors and the capacity of myelin debris clearance (Lampron et al., 2015; Cantuti-Castelvetri et al., 2018; Figure 2). Astrocytes can further participate in microglial recruitment at the lesion to promote debris clearance (Skripuletz et al., 2013), taking part in a global crosstalk. Reciprocally, the effect of extracellular vesicles produced by microglia on OPCs is modulated by astroglia (Lombardi et al., 2019). Finally, it has been recently described that microglial activation following cancer therapy can lead to astroglial activation and alter adaptive myelination highlighting the importance of inter-glial

\section{REFERENCES}

Adaikkan, C., Middleton, S. J., Marco, A., Pao, P. C., Mathys, H., Kim, D. N. W., et al. (2019). $\gamma$ entrainment binds higher-order brain regions and offers neuroprotection. Neuron 102, 929.e8-943.e8. doi: 10.1016/j.neuron.2019. 04.011

Adaikkan, C., and Tsai, L. (2019). $\gamma$ entrainment: impact on neurocircuits, glia, and therapeutic opportunities. Trends Neurosci. 43, 24-41. doi: 10.1016/j.tins. 2019.11.001

Arancibia-Cárcamo, I. L., Ford, M. C., Cossell, L., Ishida, K., Tohyama, K., and Attwell, D. (2017). Node of ranvier length as a potential regulator of myelinated axon conduction speed. Elife 6:e23329. doi: 10.7554/eLife.23329

Back, S. A., Tuohy, T. M. F., Chen, H., Wallingford, N., Craig, A., Struve, J., et al. (2005). Hyaluronan accumulates in demyelinated lesions and inhibits oligodendrocyte progenitor maturation. Nat. Med. 11, 966-972. doi: $10.1038 / \mathrm{nm} 1279$

Balia, M., Benamer, N., and Angulo, M. C. (2017). A specific GABAergic synapse onto oligodendrocyte precursors does not regulate cortical oligodendrogenesis. Glia 65, 1821-1832. doi: 10.1002/glia.23197

Balkowiec, A., and Katz, D. M. (2000). Activity-dependent release of endogenous brain-derived neurotrophic factor from primary sensory neurons detected by ELISA in situ. J. Neurosci. 20, 7417-7423. doi: 10.1523/JNEUROSCI.20-1907417.2000

Bar, E., and Barak, B. (2019). Microglia roles in synaptic plasticity and myelination in homeostatic conditions and neurodevelopmental disorders. Glia 67, 2125-2141. doi: 10.1002/glia.23637

Baraban, M., Koudelka, S., and Lyons, D. A. (2018). Ca ${ }^{2+}$ activity signatures of myelin sheath formation and growth in vivo. Nat. Neurosci. 21, 19-25. doi: 10.1038/s41593-017-0040-x

Barak, B., Zhang, Z., Liu, Y., Nir, A., Trangle, S. S., Ennis, M., et al. (2019). Neuronal deletion of Gtf2i, associated with Williams syndrome, causes behavioral and myelin alterations rescuable by a remyelinating drug. Nat. Neurosci. 22, 700-708. doi: 10.1038/s41593-019-0380-9

Barres, B. A. (2008). The mystery and magic of glia: a perspective on their roles in health and disease. Neuron 60, 430-440. doi: 10.1016/j.neuron.2008.10.013

Barres, B. A., and Raff, M. C. (1993). Proliferation of oligodendrocyte precursor cells depends on electrical activity in axons. Nature 361, 258-260. doi: $10.1038 / 361258 \mathrm{a} 0$ communication in these mechanisms (Gibson and Monje, 2019; Gibson et al., 2019).

The complex contribution of activated astrocytes and microglia in inflammatory conditions thus makes them key players in repair, able to either compromise or promote the efficacy of myelin redeposition (Franklin and Goldman, 2015). The activation states of these cells were further modulated by neuronal activity, the characterization of the complex crosstalk between glial and neuronal partners should pave the way to a better understanding of myelinic regulation and to more integrative therapeutical strategies.

\section{AUTHOR CONTRIBUTIONS}

$\mathrm{RR}, \mathrm{AD}$, and $\mathrm{CL}$ wrote the manuscript and made the figures. $\mathrm{AD}$, $\mathrm{RR}, \mathrm{CL}$, and MT proofread the manuscript.

\section{FUNDING}

The authors are funded by INSERM, ICM, ARSEP (to CL and AD), FRM fellowship, SPF20110421435 (to AD), FDT20170437332 (to MT), Prix Bouvet-Labruyère-Fondation de France (to AD), ANR JC (ANR-17-CE16-0005-01; to AD) and FRC (« Espoir en tête », Rotary Club).

Bartsch, S., Montag, D., Schachner, M., and Bartsch, U. (1997). Increased number of unmyelinated axons in optic nerves of adult mice deficient in the myelinassociated glycoprotein (MAG). Brain Res. 762, 231-234. doi: 10.1016/s00068993(97)00484-8

Bechler, M. E., Swire, M., and Ffrench-Constant, C. (2018). Intrinsic and adaptive myelination - a sequential mechanism for smart wiring in the brain. Dev. Neurobiol. 78, 68-79. doi: 10.1002/dneu.22518

Bergles, D. E., Roberts, J. D. B., Somogyl, P., and Jahr, C. E. (2000). Glutamatergic synapses on oligodendrocyte precursor cells in the hippocampus. Nature 405 , 187-191. doi: 10.1038/35012083

Blakemore, W. F., Gilson, J. M., and Crang, A. J. (2003). The presence of astrocytes in areas of demyelination influences remyelination following transplantation of oligodendrocyte progenitors. Exp. Neurol. 184, 955-963. doi: 10.1016/s00144886(03)00347-9

Brambilla, R., Morton, P. D., Ashbaugh, J. J., Karmally, S., Lambertsen, K. L., and Bethea, J. R. (2014). Astrocytes play a key role in EAE pathophysiology by orchestrating in the CNS the inflammatory response of resident and peripheral immune cells and by suppressing remyelination. Glia 62, 452-467. doi: $10.1002 /$ glia.22616

Brill, M. H., Waxman, S. G., Moore, J. W., and Joyner, R. W. (1977). Conduction velocity and spike configuration in myelinated fibres: computed dependence on internode distance. J. Neurol. Neurosurg. Psychiatry 40, 769-774. doi: 10.1136/jnnp.40.8.769

Butovsky, O., Ziv, Y., Schwartz, A., Landa, G., Talpalar, A. E., Pluchino, S., et al. (2006). Microglia activated by IL-4 or IFN- $\gamma$ differentially induce neurogenesis and oligodendrogenesis from adult stem/progenitor cells. Mol. Cell. Neurosci. 31, 149-160. doi: 10.1016/j.mcn.2005.10.006

Cajal, S. R. Y. (1894). La fine structure des centres nerveux. Proc. R. Soc. Lond. 55, 444-468. doi: 10.1098/rspl.1894.0063

Camargo, N., Goudriaan, A., van Deijk, A. L. F., Otte, W. M., Brouwers, J. F., Lodder, H., et al. (2017). Oligodendroglial myelination requires astrocytederived lipids. PLoS Biol. 15:e1002605. doi: 10.1371/journal.pbio.1002605

Cantuti-Castelvetri, L., Fitzner, D., Bosch-Queralt, M., Weil, M., Su, M., Sen, P., et al. (2018). Defective cholesterol clearance limits remyelination in the aged central nervous system. Science 359, 684-688. doi: 10.1126/science. aan 4183

Chen, T. J., Kula, B., Nagy, B., Barzan, R., Gall, A., Ehrlich, I., et al. (2018). In vivo regulation of oligodendrocyte precursor cell proliferation and differentiation by 
the AMPA-receptor subunit GluA2. Cell Rep. 25, 852.e7-861.e7. doi: 10.1016/j. celrep.2018.09.066

Chomiak, T., and Hu, B. (2009). What is the optimal value of the g-ratio for myelinated fibers in the rat CNS? A theoretical approach. PLoS One 4:e7754. doi: 10.1371/journal.pone.0007754

Chong, S. Y. C., Rosenberg, S. S., Fancy, S. P. J., Zhao, C., Shen, Y. A. A., Hahn, A. T., et al. (2012). Neurite outgrowth inhibitor Nogo-A establishes spatial segregation and extent of oligodendrocyte myelination. Proc. Natl. Acad. Sci. U S A 109, 1299-1304. doi: 10.1073/pnas.1113540109

Colonna, M., and Butovsky, O. (2017). Microglia function in the central nervous system during health and neurodegeneration. Annu. Rev. Immunol. 35, 441-468. doi: 10.1146/annurev-immunol-051116-052358

Corley, S. M., Ladiwala, U., Besson, A., and Yong, V. W. (2001). Astrocytes attenuate oligodendrocyte death in vitro through an $\alpha 6$ integrin-laminindependent mechanism. Glia 36, 281-294. doi: 10.1002/glia.1116

Cserép, C., Pósfai, B., Lénárt, N., Fekete, R., László, Z. I., Lele, Z., et al. (2020). Microglia monitor and protect neuronal function via specialized somatic purinergic junctions. Science 367, 528-537. doi: 10.1126/science.aax6752

Cullen, A. C. L., Pepper, R. E., Clutterbuck, M. T., Pitman, K. A., Oorschot, V., Auderset, L., et al. (2019). Myelin and nodal plasticity modulate action potential conduction in the adult mouse brain. bioRxiv [Preprint]. doi: 10.1101/ 726760

Czopka, T., Ffrench-Constant, C., and Lyons, D. A. (2013). Individual oligodendrocytes have only a few hours in which to generate new myelin sheaths in vivo. Dev. Cell 25, 599-609. doi: 10.1016/j.devcel.2013.05.013

Dangata, Y. Y., and Kaufman, M. H. (1997). Myelinogenesis in the optic nerve of $(\mathrm{C} 57 \mathrm{BL} \times \mathrm{CBA}) \mathrm{F} 1$ hybrid mice: a morphometric analysis. Eur. J. Morphol. 35, 3-17. doi: 10.1076/ejom.35.1.3.13057

Demerens, C., Stankoff, B., Logak, M., Anglade, P., Allinquant, B., Couraud, F., et al. (1996). Induction of myelination in the central nervous system by electrical activity. Proc. Natl. Acad. Sci. U S A 93, 9887-9892. doi: 10.1073/pnas. 93.18.9887

Dieni, S., Matsumoto, T., Dekkers, M., Rauskolb, S., Ionescu, M. S., Deogracias, R., et al. (2012). BDNF and its pro-peptide are stored in presynaptic dense core vesicles in brain neurons. J. Cell Biol. 196, 775-788. doi: 10.1083/jcb.201201038

Djannatian, M., Timmler, S., Arends, M., Luckner, M., Weil, M. T., Alexopoulos, I., et al. (2019). Two adhesive systems cooperatively regulate axon ensheathment and myelin growth in the CNS. Nat. Commun. 10:4794. doi: 10.1038/s41467019-12789-Z

Domingues, H. S., Portugal, C. C., Socodato, R., and Relvas, J. B. (2016). Oligodendrocyte, astrocyte and microglia crosstalk in myelin development, damage, and repair. Front. Cell Dev. Biol. 4:71. doi: 10.3389/fcell.2016.00071

Dutta, D. J., Woo, D. H., Lee, P. R., Pajevic, S., Bukalo, O., Huffman, W. C., et al. (2018). Regulation of myelin structure and conduction velocity by perinodal astrocytes. Proc. Natl. Acad. Sci. U S A 115, 11832-11837. doi: 10.1073/pnas. 1811013115

Eilam, R., Segal, M., Malach, R., Sela, M., Arnon, R., and Aharoni, R. (2018). Astrocyte disruption of neurovascular communication is linked to cortical damage in an animal model of multiple sclerosis. Glia 66, 1098-1117. doi: 10.1002/glia.23304

Etxeberria, A., Hokanson, K. C., Dao, D. Q., Mayoral, S. R., Mei, F., Redmond, S. A., et al. (2016). Dynamic modulation of myelination in response to visual stimuli alters optic nerve conduction velocity. J. Neurosci. 36, 6937-6948. doi: 10.1523/JNEUROSCI.0908-16.2016

Fard, M. K., van der Meer, F., Sánchez, P., Cantuti-Castelvetri, L., Mandad, S., Jäkel, S., et al. (2017). BCAS1 expression defines a population of early myelinating oligodendrocytes in multiple sclerosis lesions. Sci. Transl. Med. 9:eaam7816. doi: 10.1126/scitranslmed.aam7816

Feldman, D. E. (2012). The spike-timing dependence of plasticity. Neuron 75 , 556-571. doi: 10.1016/j.neuron.2012.08.001

Fields, R. D., Araque, A., Johansen-Berg, H., Lim, S. S., Lynch, G., Nave, K. A., et al. (2014). Glial biology in learning and cognition. Neuroscientist 20, 426-431. doi: $10.1177 / 1073858413504465$

Fields, R. D., and Stevens, B. (2000). ATP: an extracellular signaling molecule between neurons and glia. Trends Neurosci. 23, 625-633. doi: 10.1016/s01662236(00)01674-x

Ford, M. C., Alexandrova, O., Cossell, L., Stange-Marten, A., Sinclair, J., KoppScheinpflug, C., et al. (2015). Tuning of Ranvier node and internode properties in myelinated axons to adjust action potential timing. Nat. Commun. 6:8073. doi: $10.1038 /$ ncomms 9073

Franklin, R. J. M., Crang, A. J., and Blakemore, W. F. (1991). Transplanted type-1 astrocytes facilitate repair of demyelinating lesions by host oligodendrocytes in adult rat spinal cord. J. Neurocytol. 20, 420-430. doi: 10.1007/bf013 55538

Franklin, R. J. M., and Goldman, S. A. (2015). Glia disease and repairremyelination. Cold Spring Harb. Perspect. Biol. 7:a020594. doi: 10.1101/ cshperspect.a020594

Fulmer, C. G., VonDran, M. W., Stillman, A. A., Huang, Y., Hempstead, B. L., and Dreyfus, C. F. (2014). Astrocyte-Derived BDNF supports myelin protein synthesis after cuprizone-induced demyelination. J. Neurosci. 34, 8186-8196. doi: 10.1523/JNEUROSCI.4267-13.2014

Fünfschilling, U., Supplie, L. M., Mahad, D., Boretius, S., Saab, A. S., Edgar, J., et al. (2012). Glycolytic oligodendrocytes maintain myelin and long-term axonal integrity. Nature 485, 517-521. doi: 10.1038/nature11007

Gallo, V., Mangin, J. M., Kukley, M., and Dietrich, D. (2008). Synapses on NG2-expressing progenitors in the brain: multiple functions? J. Physiol. 586, 3767-3781. doi: 10.1113/jphysiol.2008.158436

Gard, A. L., Burrell, M. R., Pfeiffer, S. E., Rudge, J. S., and Williams, W. C. II. (1995). Astroglial control of oligodendrocyte survival mediated by PDGF and leukemia inhibitory factor-like protein. Development 121, 2187-2197.

Garey, L. (2010). When cortical development goes wrong: schizophrenia as a neurodevelopmental disease of microcircuits. J. Anat. 217, 324-333. doi: 10.1111/j.1469-7580.2010.01231.x

Garza, K. M., Zhang, L., Borron, B., Wood, L. B., and Singer, A. C. (2020). $\gamma$ visual stimulation induces a neuroimmune signaling profile distinct from acute neuroinflammation. J. Neurosci. 40, 1211-1225. doi: 10.1523/JNEUROSCI. 1511-19.2019

Geha, S., Pallud, J., Junier, M. P., Devaux, B., Leonard, N., Chassoux, F., et al. (2010). $\mathrm{NG}^{+} / \mathrm{Olig}^{+}$cells are the major cycle-related cell population of the adult human normal brain. Brain Pathol. 20, 399-411. doi: 10.1111/j.17503639.2009.00295.x

Geraghty, A. C., Gibson, E. M., Ghanem, R. A., Greene, J. J., Ocampo, A., Goldstein, A. K., et al. (2019). Loss of adaptive myelination contributes to methotrexate chemotherapy-related cognitive impairment. Neuron 103, 250.e8-265.e8. doi: 10.1016/j.neuron.2019.04.032

Gibson, E. M., and Monje, M. (2019). Emerging mechanistic underpinnings and therapeutic targets for chemotherapy-related cognitive impairment. Curr. Opin. Oncol. 31, 531-539. doi: 10.1097/cco.0000000000000578

Gibson, E. M., Nagaraja, S., Ocampo, A., Tam, L. T., Wood, L. S., Pallegar, P. N., et al. (2019). Methotrexate chemotherapy induces persistent tri-glial dysregulation that underlies chemotherapy-related cognitive impairment. Cell 176, 43.e13-55.e13. doi: 10.1016/j.cell.2018.10.049

Gibson, E. M., Purger, D., Mount, C. W., Goldstein, A. K., Lin, G. L., Wood, L. S., et al. (2014). Neuronal activity promotes oligodendrogenesis and adaptive myelination in the mammalian brain. Science 344:1252304 doi: 10.1126/science. 1252304

Giorgetti, E., Panesar, M., Zhang, Y., Joller, S., Ronco, M., Obrecht, M., et al. (2019). Modulation of microglia by voluntary exercise or CSF1R inhibition prevents age-related loss of functional motor units. Cell Rep. 29, 1539.e7-1554.e7. doi: 10.1016/j.celrep.2019.10.003

Goebbels, S., Wieser, G. L., Pieper, A., Spitzer, S., Weege, B., Yan, K., et al. (2017). A neuronal $\mathrm{PI}(3,4,5) \mathrm{P}_{3}$-dependent program of oligodendrocyte precursor recruitment and myelination. Nat. Neurosci. 20, 10-15. doi: 10.1038/ nn. 4425

Goncalves, M. B., Wu, Y., Clarke, E., Grist, J., Hobbs, C., Trigo, D., et al. (2019). Regulation of myelination by exosome associated retinoic acid release from NG2-positive cells. J. Neurosci. 39, 3013-3027. doi: 10.1523/JNEUROSCI.292218.2019

Gosselin, D., Link, V. M., Romanoski, C. E., Fonseca, G. J., Eichenfield, D. Z., Spann, N. J., et al. (2014). Environment drives selection and function of enhancers controlling tissue-specific macrophage identities. Cell 159, 1327-1340. doi: 10.1016/j.cell.2014.11.023

Gosselin, D., Skola, D., Coufal, N. G., Holtman, I. R., Schlachetzki, J. C. M., Sajti, E., et al. (2017). An environment-dependent transcriptional network specifies human microglia identity. Science 356:eaal3222. doi: 10.1126/science. aal3222 
Gravel, C., Sasseville, R., and Hawkes, R. (1990). Maturation of the corpus callosum of the rat: II. Influence of thyroid hormones on the number and maturation of axons. J. Comp. Neurol. 291, 147-161. doi: 10.1002/cne. 902910110

Gyllensten, L., and Malmfors, T. (1963). Myelinization of the optic nerve and its dependence on visual function-a quantitative investigation in mice. J. Embryol. Exp. Morphol. 11, 255-266.

Hagemeyer, N., Hanft, K. M., Akriditou, M. A., Unger, N., Park, E. S., Stanley, E. R., et al. (2017). Microglia contribute to normal myelinogenesis and to oligodendrocyte progenitor maintenance during adulthood. Acta Neuropathol. 134, 441-458. doi: 10.1007/s00401-017-1747-1

Hamilton, N. B., Clarke, L. E., Arancibia-Carcamo, I. L., Kougioumtzidou, E., Matthey, M., Káradóttir, R., et al. (2017). Endogenous GABA controls oligodendrocyte lineage cell number, myelination, and CNS internode length. Glia 65, 309-321. doi: 10.1002/glia.23093

Hamilton, S. P., and Rome, L. H. (1994). Stimulation of in vitro myelin synthesis by microglia. Glia 11, 326-335. doi: 10.1002/glia.440110405

Harris, J. J., and Attwell, D. (2012). The energetics of CNS white matter. J. Neurosci. 32, 356-371. doi: 10.1523/JNEUROSCI.3430-11.2012

Hartline, D. K., and Colman, D. R. (2007). Rapid conduction and the evolution of giant axons and myelinated fibers. Curr. Biol. 17, R29-R35. doi: 10.1016/j.cub. 2006.11.042

Hartmann, M., Heumann, R., and Lessmann, V. (2001). Synaptic secretion of BDNF after high-frequency stimulation of glutamatergic synapses. EMBO J. 20, 5887-5897. doi: 10.1093/emboj/20.21.5887

Hildebrand, C., Bowe, C. M., and Remahl, I. N. (1994). Myelination and myelin sheath remodelling in normal and pathological PNS nerve fibres. Prog. Neurobiol. 43, 85-141. doi: 10.1016/0301-0082(94)90010-8

Hildebrand, C., Remahl, S., Persson, H., and Bjartmar, C. (1993). Myelinated nerve fibres in the CNS. Prog. Neurobiol. 40, 319-384. doi: 10.1016/03010082(93)90015-k

Hill, R. A., Li, A. M., and Grutzendler, J. (2018). Lifelong cortical myelin plasticity and age-related degeneration in the live mammalian brain. Nat. Neurosci. 21, 683-695. doi: 10.1038/s41593-018-0120-6

Hill, R. A., Patel, K. D., Goncalves, C. M., Grutzendler, J., and Nishiyama, A. (2014). Modulation of oligodendrocyte generation during a critical temporal window after NG2 cell division. Nat. Neurosci. 17, 1518-1527. doi: 10.1038/nn. 3815

Hines, J. H., Ravanelli, A. M., Schwindt, R., Scott, E. K., and Appel, B. (2015). Neuronal activity biases axon selection for myelination in vivo. Nat. Neurosci. 18, 683-689. doi: 10.1038/nn.3992

Hoche, T., Marisca, R., Agirre, E., Hoodless, L. J., Barkey, W., Auer, F., et al. (2019). Functionally distinct subgroups of oligodendrocyte precursor cells integrate neural activity and execute myelin formation tobias. bioRxiv [Preprint]. doi: $10.1101 / 689505$

Honjin, R., Sakato, S., and Yamashita, T. (1977). Electron microscopy of the mouse optic nerve: a quantitative study of the total optic nerve fibers. Arch. Histol. Jpn. 40, 321-332. doi: 10.1679/aohc1950.40.321

Howell, O. W., Rundle, J. L., Garg, A., Komada, M., Brophy, P. J., and Reynolds, R. (2010). Activated microglia mediate axoglial disruption that contributes to axonal injury in multiple sclerosis. J. Neuropathol. Exp. Neurol. 69, 1017-1033. doi: 10.1097/nen.0b013e3181f3a5b1

Hughes, A. N., and Appel, B. (2019). Oligodendrocytes express synaptic proteins that modulate myelin sheath formation. Nat. Commun. 10:4125. doi: 10.1038/s41467-019-12059-y

Hughes, E. G., Orthmann-Murphy, J. L., Langseth, A. J., and Bergles, D. E. (2018). Myelin remodeling through experience-dependent oligodendrogenesis in the adult somatosensory cortex. Nat. Neurosci. 21, 696-706. doi: 10.1038/s41593018-0121-5

Huxley, B. Y. A. F., and Stampfli, A. D. R. (1948). Evidence for saltatory conduction in peripheral myelinated nerves fibers. J. Physiol. 108, 315-339. doi: 10.1113/jphysiol.1949.sp004335

Iaccarino, H. F., Singer, A. C., Martorell, A. J., Rudenko, A., Gao, F., Gillingham, T. Z., et al. (2016). $\gamma$ frequency entrainment attenuates amyloid load and modifies microglia. Nature 540, 230-235. doi: 10.1038/nature 20587

Ikeda, O., Murakami, M., Ino, H., Yamazaki, M., Koda, M., Nakayama, C., et al. (2002). Effects of brain-derived neurotrophic factor (BDNF) on compression- induced spinal cord injury: BDNF attenuates down-regulation of superoxide dismutase expression and promotes up-regulation of myelin basic protein expression. J. Neuropathol. Exp. Neurol. 61, 142-153. doi: 10.1093/jnen/61. 2.142

Ishibashi, T., Dakin, K. A., Stevens, B., Lee, P. R., Kozlov, S. V., Stewart, C. L., et al. (2006). Astrocytes promote myelination in response to electrical impulses. Neuron 49, 823-832. doi: 10.1016/j.neuron.2006.02.006

Jäkel, S., Agirre, E., Mendanha Falcão, A., van Bruggen, D., Lee, K. W., Knuesel, I., et al. (2019). Altered human oligodendrocyte heterogeneity in multiple sclerosis. Nature 566, 543-547. doi: 10.1038/s41586-0190903-2

Janova, H., Arinrad, S., Balmuth, E., Mitjans, M., Hertel, J., Habes, M., et al. (2018). Microglia ablation alleviates myelin-associated catatonic signs in mice. J. Clin. Invest. 128, 734-745. doi: 10.1172/jci97032

Jiang, P., Chen, C., Liu, X. B., Pleasure, D. E., Liu, Y., and Deng, W. (2016). Human iPSC-derived immature astroglia promote oligodendrogenesis by increasing TIMP-1 Secretion. Cell Rep. 15, 1303-1315. doi: 10.1016/j.celrep.2016. 04.011

Kandel, E. R., Dudai, Y., and Mayford, M. R. (2014). The molecular and systems biology of memory. Cell 157, 163-186. doi: 10.1016/j.cell.2014.03.001

Kang, S. H., Fukaya, M., Yang, J. K., Rothstein, J. D., and Bergles, D. E. (2010). NG2+ CNS glial progenitors remain committed to the oligodendrocyte lineage in postnatal life and following neurodegeneration. Neuron 68, 668-681. doi: 10.1016/j.neuron.2010.09.009

Káradóttir, R., Hamilton, N. B., Bakiri, Y., and Attwell, D. (2008). Spiking and nonspiking classes of oligodendrocyte precursor glia in CNS white matter. Nat. Neurosci. 11, 450-456. doi: 10.1038/nn2060

Kim, R. Y., Hoffman, A. S., Itoh, N., Ao, Y., Spence, R., Sofroniew, M. V., et al. (2014). Astrocyte CCL2 sustains immune cell infiltration in chronic experimental autoimmune encephalomyelitis. J. Neuroimmunol. 274, 53-61. doi: 10.1016/j.jneuroim.2014.06.009

Klingseisen, A., Ristoiu, A., Kegel, L., Sherman, D. L., Rubio-Brotons, M., Almeida, R. G., et al. (2019). Oligodendrocyte neurofascin independently regulates both myelin targeting and sheath growth in the CNS. Dev. Cell 51, 730.e6-744.e6. doi: 10.1016/j.devcel.2019.10.016

Korrell, K. V., Disser, J., Parley, K., Vadisiute, A., Requena-Komuro, M., Fodder, H., et al. (2019). Differential effect on myelination through abolition of activity-dependent synaptic vesicle release or reduction of overall electrical activity of selected cortical projections in the mouse. J. Anat. 235, 452-467. doi: 10.1111/joa.12974

Korte, M., and Schmitz, D. (2016). Cellular and system biology of memory: timing, molecules, and beyond. Physiol. Rev. 96, 647-693. doi: 10.1152/physrev.00 010.2015

Koudelka, S., Voas, M. G. G., Almeida, R. G. G., Baraban, M., Soetaert, J., Meyer, M. P. P., et al. (2016). Individual neuronal subtypes exhibit diversity in CNS myelination mediated by synaptic vesicle release. Curr. Biol. 26, 1447-1455. doi: 10.1016/j.cub.2016.03.070

Kougioumtzidou, E., Shimizu, T., Hamilton, N. B., Tohyama, K., Sprengel, R., Monyer, H., et al. (2017). Signalling through AMPA receptors on oligodendrocyte precursors promotes myelination by enhancing oligodendrocyte survival. Elife 6:e28080. doi: 10.7554/eLife.28080

Kramann, N., Menken, L., Pförtner, R., Schmid, S. N., Stadelmann, C., Wegner, C., et al. (2019). Glial fibrillary acidic protein expression alters astrocytic chemokine release and protects mice from cuprizone-induced demyelination. Glia 67, 1308-1319. doi: 10.1002/glia.23605

Krasnow, A. M., Ford, M. C., Valdivia, L. E., Wilson, S. W., and Attwell, D. (2018). Regulation of developing myelin sheath elongation by oligodendrocyte calcium transients in vivo. Nat. Neurosci. 21, 24-30. doi: 10.1038/s41593-0170031-y

Lampron, A., Larochelle, A., Laflamme, N., Préfontaine, P., Plante, M. M., Sánchez, M. G., et al. (2015). Inefficient clearance of myelin debris by microglia impairs remyelinating processes. J. Exp. Med. 212, 481-495. doi: 10.1084/jem. 20141656

Lawson, L. J., Perry, V. H., Dri, P., and Rlksn, S. G. (1990). Heterogeneity in the distribution and morphology of microglia in the normal adult mouse brain. Neuroscience 39, 151-170. doi: 10.1016/0306-4522(90)90229-w

Lee, S., Leach, M. K., Redmond, S. A., Chong, S. Y. C., Mellon, S. H., Tuck, S. J., et al. (2012). A culture system to study oligodendrocyte myelination processes 
using engineered nanofibers. Nat. Methods 9, 917-922. doi: 10.1038/nmeth. 2105

Lee, Y., Morrison, B. M., Li, Y., Lengacher, S., Farah, M. H., Hoffman, P. N., et al. (2012). Oligodendroglia metabolically support axons and contribute to neurodegeneration. Nature 487, 443-448. doi: 10.1038/nature11314

Li, Y., Du, X. F., Liu, C. S., Wen, Z. L., and Du, J. L. (2012). Reciprocal regulation between resting microglial dynamics and neuronal activity in vivo. Dev. Cell 23, 1189-1202. doi: 10.1016/j.devcel.2012.10.027

Liddelow, S. A., Guttenplan, K. A., Clarke, L. E., Bennett, F. C., Bohlen, C. J., Schirmer, L., et al. (2017). Neurotoxic reactive astrocytes are induced by activated microglia. Nature 541, 481-487. doi: 10.1038/nature21029

Lin, S. C., and Bergles, D. E. (2004). Synaptic signaling between GABAergic interneurons and oligodendrocyte precursor cells in the hippocampus. Nat. Neurosci. 7, 24-32. doi: 10.1038/nn1162

Liu, J., Dietz, K., Deloyht, J. M., Pedre, X., Kelkar, D., Kaur, J., et al. (2012). Impaired adult myelination in the prefrontal cortex of socially isolated mice. Nat. Neurosci. 15, 1621-1623. doi: 10.1038/nn.3263

Liu, Y. U., Ying, Y., Li, Y., Eyo, U. B., Chen, T., Zheng, J., et al. (2019). Neuronal network activity controls microglial process surveillance in awake mice via norepinephrine signaling. Nat. Neurosci. 22, 1771-1781. doi: 10.1038/s41593019-0511-3

Locatelli, G., Theodorou, D., Kendirli, A., Jordão, M. J. C., Staszewski, O., Phulphagar, K., et al. (2018). Mononuclear phagocytes locally specify and adapt their phenotype in a multiple sclerosis model. Nat. Neurosci. 21, 1196-1208. doi: 10.1038/s41593-018-0212-3

Lombardi, M., Parolisi, R., Scaroni, F., Bonfanti, E., Gualerzi, A., Gabrielli, M., et al. (2019). Detrimental and protective action of microglial extracellular vesicles on myelin lesions: astrocyte involvement in remyelination failure. Acta Neuropathol. 138, 987-1012. doi: 10.1007/s00401-019-02049-1

Lundgaard, I., Luzhynskaya, A., Stockley, J. H., Wang, Z., Evans, K. A., Swire, M., et al. (2013). Neuregulin and BDNF induce a switch to NMDA receptor-dependent myelination by oligodendrocytes. PLoS Biol. 11:e1001743. doi: 10.1371/journal.pbio.1001743

Mangin, J. M., Li, P., Scafidi, J., and Gallo, V. (2012). Experience-dependent regulation of NG2 progenitors in the developing barrel cortex. Nat. Neurosci. 15, 1192-1194. doi: 10.1038/nn.3190

Martorell, A. J., Paulson, A. L., Suk, H. J., Abdurrob, F., Drummond, G. T., Guan, W., et al. (2019). Multi-sensory $\gamma$ stimulation ameliorates Alzheimer'sassociated pathology and improves cognition. Cell 177, 256.e22-271.e22. doi: 10.1016/j.cell.2019.02.01

Matthews, M. A. (1968). An electron microscopic study of the relationship between axon diameter and the initiation of myelin production in the peripheral nervous system. Anat. Rec. 161, 337-351. doi: 10.1002/ar. 1091610306

Matthews, M. A., and Duncan, D. (1971). A quantitative study of morphological changes accompanying the initiation and progress of myelin production in the dorsal funiculus of the rat spinal cord. J. Comp. Neurol. 142, 1-22. doi: 10.1002/cne.901420102

Mayoral, S. R., Etxeberria, A., Shen, Y. A. A., and Chan, J. R. (2018). Initiation of CNS myelination in the optic nerve is dependent on axon caliber. Cell Rep. 25, 544.e3-550.e3. doi: 10.1016/j.celrep.2018.09.052

McKenzie, I. A., Ohayon, D., Li, H., de Faria, J. P., Emery, B., Tohyama, K., et al. (2014). Motor skill learning requires active central myelination. Science 346, 318-322. doi: 10.1126/science. 1254960

McTigue, D. M., Horner, P. J., Stokes, B. T., and Gage, F. H. (1998). Neurotrophin-3 and brain-derived neurotrophic factor induce oligodendrocyte proliferation and myelination of regenerating axons in the contused adult rat spinal cord. J. Neurosci. 18, 5354-5365. doi: 10.1523/JNEUROSCI.18-1405354.1998

Menichella, D. M., Majdan, M., Awatramani, R., Goodenough, D. A., Sirkowski, E., Scherer, S. S., et al. (2006). Genetic and physiological evidence that oligodendrocyte gap junctions contribute to spatial buffering of potassium released during neuronal activity. J. Neurosci. 26, 10984-10991. doi: 10.1523/JNEUROSCI.0304-06.2006

Mensch, S., Baraban, M., Almeida, R., Czopka, T., Ausborn, J., El Manira, A., et al. (2015). Synaptic vesicle release regulates myelin sheath number of individual oligodendrocytes in vivo. Nat. Neurosci. 18, 628-630. doi: 10.1038/ nn.3991
Meyer, N., Richter, N., Fan, Z., Siemonsmeier, G., Pivneva, T., Jordan, P., et al. (2018). Oligodendrocytes in the mouse corpus callosum maintain axonal function by delivery of glucose. Cell Rep. 22, 2383-2394. doi: 10.1016/j.celrep. 2018.02.022

Michailov, G. V., Sereda, M. W., Brinkmann, B. G., Fischer, T. M., Haug, B., Birchmeier, C., et al. (2004). Axonal neuregulin-1 regulates myelin sheath thickness. Science 304, 700-703. doi: 10.1126/science.1095862

Micheva, K. D., Wolman, D., Mensh, B. D., Pax, E., Buchanan, J., Smith, S. J., et al. (2016). A large fraction of neocortical myelin ensheathes axons of local inhibitory neurons. Elife 5:e15784. doi: 10.7554/eLife.15784

Miron, V. E. (2017). Microglia-driven regulation of oligodendrocyte lineage cells, myelination, and remyelination. J. Leukoc. Biol. 101, 1103-1108. doi: 10.1189/jlb.3ri1116-494r

Miron, V. E., Boyd, A., Zhao, J. W., Yuen, T. J., Ruckh, J. M., Shadrach, J. L., et al. (2013). M2 microglia and macrophages drive oligodendrocyte differentiation during CNS remyelination. Nat. Neurosci. 16, 1211-1218. doi: 10.1038/nn.3469

Miron, V. E., and Franklin, R. J. M. (2014). Macrophages and CNS remyelination. J. Neurochem. 130, 165-171. doi: 10.1111/jnc.12705

Mitew, S., Gobius, I., Fenlon, L. R., McDougall, S. J., Hawkes, D., Xing, Y. L., et al. (2018). Pharmacogenetic stimulation of neuronal activity increases myelination in an axon-specific manner. Nat. Commun. 9:306. doi: 10.1038/s41467-01702719-2

Modi, K. K., Sendtner, M., and Pahan, K. (2013). Up-regulation of ciliary neurotrophic factor in astrocytes by aspirin. J. Biol. Chem. 288, 18533-18545. doi: $10.1074 /$ jbc.m112.447268

Molina-Gonzalez, I., and Miron, V. E. (2019). Astrocytes in myelination and remyelination. Neurosci. Lett. 713:134532. doi: 10.1016/j.neulet.2019.134532

Moore, J. W., Joyner, R. W., Brill, M. H., Waxman, S. D., and Najar-Joa, M. (1978). Simulations of conduction in uniform myelinated fibers. Relative sensitivity to changes in nodal and internodal parameters. Biophys. J. 21, 147-160. doi: 10.1016/s0006-3495(78)85515-5

Moore, S., Meschkat, M., Ruhwedel, T., Tzvetanova, I. D., Trevisiol, A., Battefeld, A., et al. (2019). A role of oligodendrocytes in information processing independent of conduction velocity. bioRxiv 736975 [Preprint]. doi: 10.1101/736975

Morgan, J. T., Chana, G., Pardo, C. A., Achim, C., Semendeferi, K., Buckwalter, J., et al. (2010). Microglial activation and increased microglial density observed in the dorsolateral prefrontal cortex in autism. Biol. Psychiatry 68, 368-376. doi: 10.1016/j.biopsych.2010.05.024

Morris, G. P., Clark, I. A., Zinn, R., and Vissel, B. (2013). Microglia: a new frontier for synaptic plasticity, learning and memory, and neurodegenerative disease research. Neurobiol. Learn. Mem. 105, 40-53. doi: 10.1016/j.nlm.2013.07.002

Mount, C. W., Yalçın, B., Cunliffe-Koehler, K., Sundaresh, S., and Monje, M. (2019). Monosynaptic tracing maps brain-wide afferent oligodendrocyte precursor cell connectivity. Elife 8:e49291. doi: 10.7554/elife.49291

Nagy, B., Hovhannisyan, A., Barzan, R., Chen, T. J., and Kukley, M. (2017). Different patterns of neuronal activity trigger distinct responses of oligodendrocyte precursor cells in the corpus callosum. PLoS Biol. 15:e2001993. doi: 10.1371/journal.pbio.2001993

Nawaz, S., Sánchez, P., Schmitt, S., Snaidero, N., Mitkovski, M., Velte, C., et al. (2015). Actin filament turnover drives leading edge growth during myelin sheath formation in the central nervous system. Dev. Cell 34, 139-151. doi: 10.1016/j.devcel.2015.05.013

Nikić, I., Merkler, D., Sorbara, C., Brinkoetter, M., Kreutzfeldt, M., Bareyre, F. M., et al. (2011). A reversible form of axon damage in experimental autoimmune encephalomyelitis and multiple sclerosis. Nat. Med. 17, 495-499. doi: $10.1038 / \mathrm{nm} .2324$

Nimmerjahn, A., Kirchhoff, F., and Helmchen, F. (2005). Resting microglial cells are highly dynamic surveillants of brain parenchyma in vivo. Science 308, 1314-1318. doi: 10.1126/science.1110647

Nortley, R., and Attwell, D. (2017). Control of brain energy supply by astrocytes. Curr. Opin. Neurobiol. 47, 80-85. doi: 10.1016/j.conb.2017.09.012

Olivares, R., Montiel, J., and Aboitiz, F. (2001). Species differences and similarities in the fine structure of the mammalian corpus callosum. Brain. Behav. Evol. 57, 98-105. doi: 10.1159/000047229

Omari, K. M., John, G. R., Sealfon, S. C., and Raine, C. S. (2005). CXC chemokine receptors on human oligodendrocytes: implications for multiple sclerosis. Brain 128, 1003-1015. doi: 10.1093/brain/awh479 
Orthmann-Murphy, J. L., Abrams, C. K., and Scherer, S. S. (2008). Gap junctions couple astrocytes and oligodendrocytes. J. Mol. Neurosci. 35, 101-116. doi: 10.1007/s12031-007-9027-5

Padovani-Claudio, D. A., Liu, L., Ransohoff, R. M., and Miller, R. H. (2006). Alterations in the oligodendrocyte lineage, myelin and white matter in adult mice lacking the chemokine receptor CXCR2. Glia 54, 471-483. doi: 10.1002/glia.20383

Pajevic, S., Basser, P. J., and Fields, R. D. (2014). Role of myelin plasticity in oscillations and synchrony of neuronal activity. Neuroscience 276, 135-147. doi: 10.1016/j.neuroscience.2013.11.007

Pandit, M. M., Inscho, E. W., Zhang, S., Seki, T., Rohatgi, R., Gusella, L., et al. (2015). Flow regulation of endothelin-1 production in the inner medullary collecting duct. Am. J. Physiol. Renal Physiol. 308, F541-F552. doi: 10.1152/ajprenal.00456.2014

Park, H., Popescu, A., and Poo, M. M. (2014). Essential role of presynaptic NMDA receptors in activity-dependent BDNF secretion and corticostriatal LTP. Neuron 84, 1009-1022. doi: 10.1016/j.neuron.2014. 10.045

Parkhurst, C. N., Yang, G., Ninan, I., Savas, J. N., Yates, J. R., Lafaille, J. J., et al. (2013). Microglia promote learning-dependent synapse formation through brain-derived neurotrophic factor. Cell 155, 1596-1609. doi: 10.1016/j.cell. 2013.11.030

Parolisi, R., and Boda, E. (2018). NG2 glia: novel roles beyond Re-/myelination. Neuroglia 1, 151-175. doi: 10.3390/neuroglia1010011

Pasquini, L. A., Millet, V., Hoyos, H. C., Giannoni, J. P., Croci, D. O., Marder, M., et al. (2011). Galectin-3 drives oligodendrocyte differentiation to control myelin integrity and function. Cell Death Differ. 18, 1746-1756. doi: $10.1038 / \mathrm{cdd} .2011 .40$

Patel, J. R., Williams, J. L., Muccigrosso, M. M., Liu, L., Sun, T., Rubin, J. B., et al. (2012). Astrocyte TNFR2 is required for CXCL12-mediated regulation of oligodendrocyte progenitor proliferation and differentiation within the adult CNS. Acta Neuropathol. 124, 847-860. doi: 10.1007/s00401-012-1034-0

Peters, A., and Sethares, C. (2004). Oligodendrocytes, their progenitors and other neuroglial cells in the aging primate cerebral cortex. Cereb. Cortex 14, 995-1007. doi: 10.1093/cercor/bhh060

Peters, A., Verderosa, A., and Sethaers, C. (2008). The neuroglial population in the primary visual cortex of the aging rhesus monkey. Glia 56, 1151-1161. doi: 10.1002/glia.20686

Prinz, M., Jung, S., and Priller, J. (2019). Microglia biology: one century of evolving concepts. Cell 179, 292-311. doi: 10.1016/j.cell.2019.08.053

Ramos-Cejudo, J., Gutiérrez-Fernández, M., Otero-Ortega, L., RodríguezFrutos, B., Fuentes, B., Vallejo-Cremades, M. T., et al. (2015). Brain-derived neurotrophic factor administration mediated oligodendrocyte differentiation and myelin formation in subcortical ischemic stroke. Stroke 46, 221-228. doi: 10.1161/strokeaha.114.006692

Ransohoff, R. M. (2016). How neuroinflammation contributes to neurodegeneration. Science 353, 777-783. doi: 10.1126/science.aag2590

Rivers, L. E., Young, K. M., Rizzi, M., Jamen, F., Psachoulia, K., Wade, A., et al. (2008). PDGFRA/NG2 glia generate myelinating oligodendrocytes and piriform projection neurons in adult mice. Nat. Neurosci. 11, 1392-1401. doi: $10.1038 / \mathrm{nn} .2220$

Rosenberg, S. S., Kelland, E. E., Tokar, E., De La Torre, A. R., and Chan, J. R. (2008). The geometric and spatial constraints of the microenvironment induce oligodendrocyte differentiation. Proc. Natl. Acad. Sci. U S A 105, 14662-14667. doi: $10.1073 /$ pnas.0805640105

Rushton, W. A. H. (1951). A theory of the effects of fibre size in medullated nerve. J. Physiol. 115, 101-122. doi: 10.1113/jphysiol.1951.sp004655

Saab, A. S., Tzvetavona, I. D., Trevisiol, A., Baltan, S., Dibaj, P., Kusch, K., et al. (2016). Oligodendroglial NMDA receptors regulate glucose import and axonal energy metabolism. Neuron 91, 119-132. doi: 10.1016/j.neuron.2016.05.016

Sakurai, Y., Nishimura, D., Yoshimura, K., Tsuruo, Y., Seiwa, C., and Asou, H. (1998). Differentiation of oligodendrocyte occurs in contact with astrocyte. J. Neurosci. Res. 52, 17-26. doi: 10.1002/(sici)10974547(19980401)52:1<17::aid-jnr3>3.0.co;2-n

Salami, M., Itami, C., Tsumoto, T., and Kimura, F. (2003). Change of conduction velocity by regional myelination yields constant latency irrespective of distance between thalamus and cortex. Proc. Natl. Acad. Sci. U S A 100, 6174-6179. doi: 10.1073/pnas.0937380100
Sampaio-Baptista, C., Khrapitchev, A. A., Foxley, S., Schlagheck, T., Scholz, J., Jbabdi, S., et al. (2013). Motor skill learning induces changes in white matter microstructure and myelination. J. Neurosci. 33, 19499-19503. doi: 10.1523/JNEUROSCI.3048-13.2013

Scholz, J., Klein, M. C., Behrens, T. E. J., and Johansen-Berg, H. (2009). Training induces changes in white-matter architecture. Nat. Neurosci. 12, 1370-1371. doi: $10.1038 / \mathrm{nn} .2412$

Seggie, J., and Berry, M. (1972). Ontogeny of interhemispheric evoked potentials in the rat: significance of myelination of the corpus callosum. Exp. Neurol. 35, 215-232. doi: 10.1016/0014-4886(72)90148-3

Selvaraju, R., Bernasconi, L., Losberger, C., Graber, P., Kadi, L., AvellanaAdalid, V., et al. (2004). Osteopontin is upregulated during in vivo demyelination and remyelination and enhances myelin formation in vitro. Mol. Cell. Neurosci. 25, 707-721. doi: 10.1016/j.mcn.2003.12.014

Shigemoto-Mogami, Y., Hoshikawa, K., Goldman, J. E., Sekino, Y., and Sato, K. (2014). Microglia enhance neurogenesis and oligodendrogenesis in the early postnatal subventricular zone. J. Neurosci. 34, 2231-2243. doi: 10.1523/jneurosci.1619-13.2014

Simon, C., Götz, M., and Dimou, L. (2011). Progenitors in the adult cerebral cortex: cell cycle properties and regulation by physiological stimuli and injury. Glia 59, 869-881. doi: 10.1002/glia.21156

Simpson, A. H., Gillingwater, T. H., Anderson, H., Cottrell, D., Sherman, D. L., Ribchester, R. R., et al. (2013). Effect of limb lengthening on internodal length and conduction velocity of peripheral nerve. J. Neurosci. 33, 4536-4539. doi: 10.1523/jneurosci.4176-12.2013

Skripuletz, T., Hackstette, D., Bauer, K., Gudi, V., Pul, R., Voss, E., et al. (2013). Astrocytes regulate myelin clearance through recruitment of microglia during cuprizone-induced demyelination. Brain 136, 147-167. doi: 10.1093/brain/aws262

Sloane, J. A., Batt, C., Ma, Y., Harris, Z. M., Trapp, B., and Vartanian, T. (2010). Hyaluronan blocks oligodendrocyte progenitor maturation and remyelination through TLR2. Proc. Natl. Acad. Sci. U S A 107, 11555-11560. doi: 10.1073/pnas.1006496107

Smith, R. S., and Koles, Z. J. (1970). Myelinated nerve fibers: computed effect of myelin thickness on conduction velocity. Am. J. Physiol. 219, 1256-1258. doi: 10.1152/ajplegacy.1970.219.5.1256

Snaidero, N., Möbius, W., Czopka, T., Hekking, L. H. P., Mathisen, C., Verkleij, D., et al. (2014). Myelin membrane wrapping of CNS axons by $\mathrm{PI}(3,4,5) \mathrm{P} 3$-dependent polarized growth at the inner tongue. Cell 156, 277-290. doi: 10.1016/j.cell.2013.11.044

Sofroniew, M. V., and Vinters, H. V. (2010). Astrocytes: biology and pathology. Acta Neuropathol. 119, 7-35. doi: 10.1007/s00401-009-0619-8

Spitzer, S. O., Sitnikov, S., Kamen, Y., Evans, K. A., Kronenberg-Versteeg, D., Dietmann, S., et al. (2019). Oligodendrocyte progenitor cells become regionally diverse and heterogeneous with age. Neuron 101, 459.e5-471.e5. doi: 10.1016/j. neuron.2018.12.020

Stankoff, B., Aigrot, M.-S., Noël, F., Wattilliaux, A., Zalc, B., and Lubetzki, C. (2002). Ciliary neurotrophic factor (CNTF) enhances myelin formation: a novel role for CNTF and CNTF-related molecules. J. Neurosci. 22, 9221-9227. doi: 10.1523/jneurosci.22-21-09221.2002

Steadman, P. E., Xia, F., Ahmed, M., Mocle, A. J., Penning, A. R. A., Geraghty, A. C., et al. (2020). Disruption of oligodendrogenesis impairs memory consolidation in adult mice. Neuron 105, 150.e6-164.e6. doi: 10.1016/j.neuron.2019.10.013

Stedehouder, J., Brizee, D., Shpak, G., and Kushner, S. A. (2018). Activitydependent myelination of parvalbumin interneurons mediated by axonal morphological plasticity. J. Neurosci. 38, 3631-3642. doi: 10.1523/jneurosci. 0074-18.2018

Stedehouder, J., Brizee, D., Slotman, J. A., Pascual-Garcia, M., Leyrer, M. L., Bouwen, B. L., et al. (2019). Local axonal morphology guides the topography of interneuron myelination in mouse and human neocortex. Elife 8:e48615. doi: 10.7554/elife.48615

Stedehouder, J., Couey, J. J., Brizee, D., Hosseini, B., Slotman, J. A., Dirven, C. M. F., et al. (2017). Fast-spiking parvalbumin interneurons are frequently myelinated in the cerebral cortex of mice and humans. Cereb. Cortex 27, 5001-5013. doi: 10.1093/cercor/bhx203

Stevens, B., Porta, S., Haak, L. L., Gallo, V., and Fields, R. D. (2002). Adenosine: a neuron-glial transmitter promoting myelination in the CNS in 
response to action potentials. Neuron 36, 855-868. doi: 10.1016/s0896-6273(02) 01067-x

Stowell, R. D., Sipe, G. O., Dawes, R. P., Batchelor, H. N., Lordy, K. A., Whitelaw, B. S., et al. (2019). Noradrenergic signaling in the wakeful state inhibits microglial surveillance and synaptic plasticity in the mouse visual cortex. Nat. Neurosci. 22, 1782-1792. doi: 10.1038/s41593-019-0514-0

Swire, M., Kotelevtsev, Y., Webb, D. J., Lyons, D. A., and Ffrench-Constant, C. (2019). Endothelin signalling mediates experience-dependent myelination in the CNS. Elife 8:e49493. doi: 10.7554/elife.49493

Takeuchi, H., Sekiguchi, A., Taki, Y., Yokoyama, S., Yomogida, Y., Komuro, N., et al. (2010). Training of working memory impacts structural connectivity. J. Neurosci. 30, 3297-3303. doi: 10.1523/JNEUROSCI.4611-09.2010

Tanaka, Y., Tozuka, Y., Takata, T., Shimazu, N., Matsumura, N., Ohta, A., et al. (2009). Excitatory GABAergic activation of cortical dividing glial cells. Cereb. Cortex 19, 2181-2195. doi: 10.1093/cercor/bhn238

Taubert, M., Draganski, B., Anwander, A., Müller, K., Horstmann, A., Villringer, A., et al. (2010). Dynamic properties of human brain structure: learning-related changes in cortical areas and associated fiber connections. J. Neurosci. 30, 11670-11677. doi: 10.1523/jneurosci.2567-10.2010

Tomassy, G. S., Berger, D. R., Chen, H.-H., Kasthuri, N., Hayworth, K. J., Vercelli, A., et al. (2014). Distinct profiles of myelin distribution along single axons of pyramidal neurons in the neocortex. Science 344, 319-324. doi: 10.1126/science.1249766

Tress, O., Maglione, M., May, D., Pivneva, T., Richter, N., Seyfarth, J., et al. (2012). Panglial gap junctional communication is essential for maintenance of myelin in the CNS. J. Neurosci. 32, 7499-7518. doi: 10.1523/jneurosci.0392-12.2012

Tripathi, R. B., Jackiewicz, M., McKenzie, I. A., Kougioumtzidou, E., Grist, M., and Richardson, W. D. (2017). Remarkable stability of myelinating oligodendrocytes in mice. Cell Rep. 21, 316-323. doi: 10.1016/j.celrep.2017. 09.050

Wake, H., Lee, P. R., and Fields, R. D. (2011). Control of local protein synthesis and initial events in myelination by action potentials. Science 333, 1647-1651. doi: 10.1126/science.1206998

Wake, H., Ortiz, F. C., Woo, D. H., Lee, P. R., Angulo, M. C., and Fields, R. D. (2015). Nonsynaptic junctions on myelinating glia promote preferential myelination of electrically active axons. Nat. Commun. 6:7844. doi: $10.1038 /$ ncomms 8844

Walshe, T. E., Ferguson, G., Connell, P., O’Brien, C., and Cahill, P. A. (2005). Pulsatile flow increases the expression of eNOS, ET-1 and prostacyclin in a novel in vitro coculture model of the retinal vasculature. Investig. Ophthalmol. Vis. Sci. 46, 375-382. doi: 10.1167/iovs.04-0806

Watkins, T. A., Emery, B., Mulinyawe, S., and Barres, B. A. (2008). Distinct stages of myelination regulated by $\gamma$-secretase and astrocytes in a rapidly myelinating CNS coculture system. Neuron 60, 555-569. doi: 10.1016/j.neuron.2008.09.011

Waxman, S. G., and Bennett, M. V. L. (1972). Relative conduction velocities of small myelinated and non-myelinated fibres in the central nervous system. Nat. New Biol. 238, 217-219. doi: 10.1038/newbio238217a0

Waxman, S. G., and Foster, R. E. (1980). Development of the axon membrane during differentiation of myelinated fibres in spinal nerve roots. Proc. R. Soc. Lond. B Biol. Sci. 209, 441-446. doi: 10.1098/rspb.1980.0105

Waxman, S. G., and Swadlow, H. A. (1976). Ultrastructure of visual callosal axons in the rabbit. Exp. Neurol. 53, 115-127. doi: 10.1016/0014-4886(76) 90287-9
Wlodarczyk, A., Holtman, I. R., Krueger, M., Yogev, N., Bruttger, J., Khorooshi, R., et al. (2017). A novel microglial subset plays a key role in myelinogenesis in developing brain. EMBO J. 36, 3292-3308. doi: 10.15252/embj. 201696056

Wu, L. M. N., Williams, A., Delaney, A., Sherman, D. L., and Brophy, P. J. (2012). Increasing internodal distance in myelinated nerves accelerates nerve conduction to a flat maximum. Curr. Biol. 22, 1957-1961. doi: 10.1016/j.cub. 2012.08.025

Xiao, L., Ohayon, D., Mckenzie, I. A., Sinclair-Wilson, A., Wright, J. L., Fudge, A. D., et al. (2016). Rapid production of new oligodendrocytes is required in the earliest stages of motor-skill learning. Nat. Neurosci. 19, 1210-1217. doi: 10.1038/nn.4351

Ye, P., Popken, G. J., Kemper, A., McCarthy, K., Popko, B., and D’Ercole, A. J. (2004). Astrocyte-specific overexpression of insulin-like growth factor-I promotes brain overgrowth and glial fibrillary acidic protein expression. J. Neurosci. Res. 78, 472-484. doi: 10.1002/jnr.20288

Yeung, M. S. Y., Zdunek, S., Bergmann, O., Bernard, S., Salehpour, M., Alkass, K., et al. (2014). Dynamics of oligodendrocyte generation and myelination in the human brain. Cell 159, 766-774. doi: 10.1016/j.cell.2014.10.011

Young, K. M., Psachoulia, K., Tripathi, R. B., Dunn, S. J., Cossell, L., Attwell, D., et al. (2013). Oligodendrocyte dynamics in the healthy adult CNS: evidence for myelin remodeling. Neuron 77, 873-885. doi: 10.1016/j.neuron.2013.01.006

Yuen, T. J., Johnson, K. R., Miron, V. E., Zhao, C., Quandt, J., Harrisingh, M. C., et al. (2013). Identification of endothelin 2 as an inflammatory factor that promotes central nervous system remyelination. Brain 136, 1035-1047. doi: 10.1093/brain/awt024

Zalc, B., Goujet, D., and Colman, D. (2008). The origin of the myelination program in vertebrates. Curr. Biol. 18, R511-R512. doi: 10.1016/j.cub.2008.04.010

Zatorre, R. J., Fields, R. D., and Johansen-Berg, H. (2012). Plasticity in gray and white: neuroimaging changes in brain structure during learning. Nat. Neurosci. 15, 528-536. doi: 10.1038/nn.3045

Zhang, Y., Chen, K., Sloan, S. A., Bennett, M. L., Scholze, A. R., O'Keeffe, S., et al. (2014). An RNA-sequencing transcriptome and splicing database of glia, neurons and vascular cells of the cerebral cortex. J. Neurosci. 34, 11929-11947. doi: 10.1523/JNEUROSCI.1860-14.2014

Zonouzi, M., Scafidi, J., Li, P., McEllin, B., Edwards, J., Dupree, J. L., et al. (2015). GABAergic regulation of cerebellar NG2 cell development is altered in perinatal white matter injury. Nat. Neurosci. 18, 674-682. doi: 10.1038/nn.3990

Zuchero, J. B., Fu, M. M., Sloan, S. A., Ibrahim, A., Olson, A., Zaremba, A., et al. (2015). CNS myelin wrapping is driven by actin disassembly. Dev. Cell 34, 152-167. doi: 10.1016/j.devcel.2015.06.011

Conflict of Interest: The authors declare that the research was conducted in the absence of any commercial or financial relationships that could be construed as a potential conflict of interest.

Copyright (C) 2020 Ronzano, Thetiot, Lubetzki and Desmazieres. This is an open-access article distributed under the terms of the Creative Commons Attribution License (CC BY). The use, distribution or reproduction in other forums is permitted, provided the original author(s) and the copyright owner(s) are credited and that the original publication in this journal is cited, in accordance with accepted academic practice. No use, distribution or reproduction is permitted which does not comply with these terms. 